\title{
Rapid simultaneous determination of indacaterol maleate and glycopyrronium bromide in inhaler capsules using a validated stability-indicating monolithic LC method
}

\author{
Sahar Zayed ${ }^{1 *}$ and Fathalla Belal ${ }^{2}$
}

\begin{abstract}
Background: Chronic obstructive pulmonary disease (COPD) is a major cause of morbidity and mortality worldwide. A combination of indacaterol maleate with glycopyrronium bromide has recently been approved as a once-daily maintenance therapy in patients with COPD. The very low dose ( $\mathrm{gg}$ level/capsule) renders the analysis of such products challenges. This study reports for the first time about HPLC method for the quality control of such combination and it is a stability indicating at the same time.

Results: A rapid, simple, precise and reproducible HPLC method was developed and validated for simultaneous determination of indacaterol maleate and glycopyrronium bromide using tenoxicam as an internal standard. The chromatographic separation was achieved on an onyx monolithic C18 column (100 $\times 4.6 \mathrm{~mm})$ using a mobile phase consisting of acetonitrile and $30 \mathrm{mM}$ phosphate buffer $(\mathrm{pH} 3.5)(30: 70, \mathrm{v} / \mathrm{v})$, run at a flow rate of $2 \mathrm{~mL} / \mathrm{min}$ with UV detection at $210 \mathrm{~nm}$. The total analysis time was less than $3 \mathrm{~min}$. The HPLC method was validated for linearity, limits of detection and quantitation, precision, accuracy, system suitability and robustness. Calibration curves were obtained in the concentration ranges of $1-44 \mu \mathrm{g} / \mathrm{mL}$ for indacaterol maleate and $0.5-20 \mu \mathrm{g} / \mathrm{mL}$ for glycopyrronium bromide. Stability tests were done through exposure of the analyte solution for different stress conditions and the results indicate no interference of degradants with HPLC method.
\end{abstract}

Conclusions: The method was successfully applied for the quantitative analysis of indacaterol maleate and glycopyrronium bromide both individually and in a combined pharmaceutical inhaler capsules to support the quality control and to assure the therapeutic efficacy of the two drugs. The simple procedure involved in sample preparation and the short run-time added the important property of high throughput to the method.

Keywords: Indacaterol maleate, Glycopyrronium bromide, HPLC, Monolithic column, Stability indicating, Inhaler capsules

\section{Background}

Chronic obstructive pulmonary disease (COPD) is a prevalent lung disease caused by chronic airway and pulmonary inflammation which lead to progressive airflow limitation. Long-acting inhaled bronchodilators are the recommended first-line maintenance

\footnotetext{
*Correspondence: s1zayed@yahoo.com

1 Unit of Drug Analysis, Faculty of Pharmacy, University of Mansoura, Mansoura 35516, Egypt

Full list of author information is available at the end of the article
}

treatment for COPD [1]. Indacaterol maleate (IND), 5-\{(1R)-2-[(5,6-diethyl-2,3-dihydro-1H-inden-2-yl) amino]-1-hydroxyethyl\}-8-hydroxy-2(1H)-quinolinone maleate, is the first ultra-long-acting $\beta 2$-agonist bronchodilator that has been approved by the U.S. Food and Drug Administration (FDA) in July 2011 [2]. Glycopyrronium bromide (GLY), 3-[(Cyclopentylhydroxyphenylacetyl) oxy]-1,1-dimethyl-pyrrolidinium bromide, a new long-acting muscarinic antagonist was approved in Europe in 2012 for maintenance bronchodilator 
treatment in patients with moderate to severe COPD [3]. Recently, the combination of IND and GLY as a dual-bronchodilator therapy is the preferred choice for COPD treatment because of its powerful bronchodilator effects and a simple once-daily inhalation regimen [4]. The chemical structures of both drugs are shown in Fig. 1.

Few analytical methods have been reported in the literature for the individual determination of IND or GLY. These methods include: spectrophotometry [5, 6], HPLC [7], GC [8], spectrofluorometry [5] and HPLC-MS methods [9-14]. IND is not cited in any pharmacopoeia while GLY is cited in European Pharmacopoeia (E.P.), British Pharmacopoeia (B.P) and United States Pharmacopoeia (U.S.P.). However, no HPLC method for simultaneous determination of IND and GLY in combined dosage forms has been reported so far.

High-performance liquid chromatography (HPLC) is usually the analytical method of choice for pharmaceutical quality control [15]. It is a demand of the time to develop high-throughput HPLC methods with high efficiency. Monolithic HPLC columns are considered as one of the modern approaches for fast analysis and an
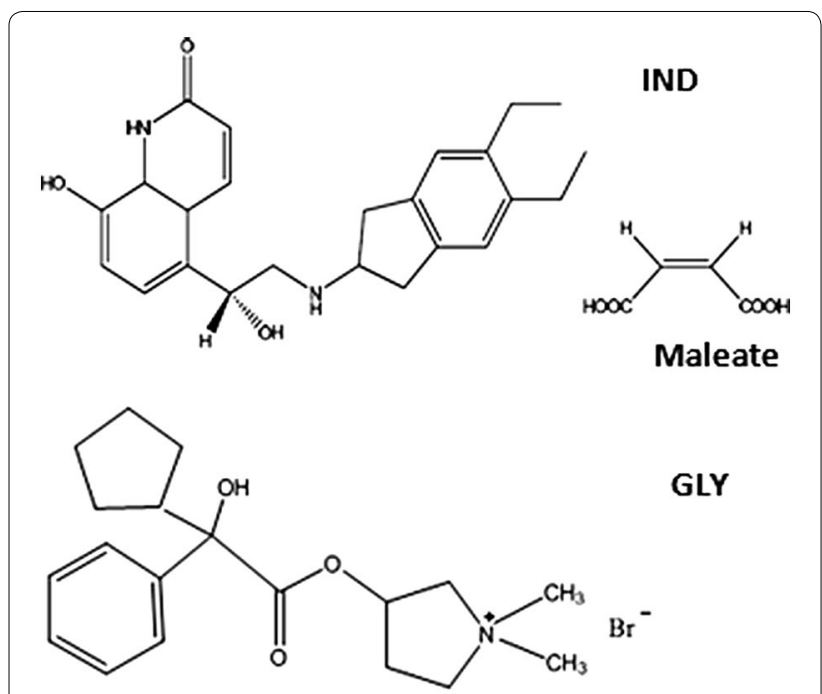

GLY

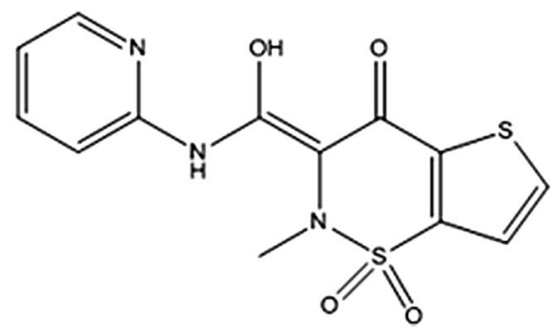

IS

Fig. 1 Chemical structures of indacaterol maleate (IND), glycopyrronium bromide (GLY) and tenoxicam (IS) interesting alternative to particulate-based HPLC columns [16]. Due to their rigid and porous structure, they enable higher rates of mass transfer at lower pressure drops as well as high efficiencies even at elevated flow rates [17]. This enhances the speed of the separation process and reduces backpressure and unspecific binding without sacrificing resolution $[18,19]$.

The present study describes, for the first time, a rapid, simple and stability-indicating HPLC method using a monolithic column with UV detection. The proposed HPLC method allowed the quantitative determination of the two drugs in their commercial inhaler capsules with satisfactory accuracy and precision. Thus, the developed method can be used for routine analysis laboratories and quality control purposes.

\section{Experimental \\ Apparatus}

Chromatographic analyses were carried out using a Shimadzu Prominence HPLC system (Shimadzu Corporation, Japan) with a LC-20 AD pump, DGU-20 A5 degasser, CBM-20A interface, a column oven (CTO20A) and SPD-20A UV-VIS detector with $20 \mu \mathrm{L}$ injection loop. An ultrasonicator from Merck L-7612 and a $\mathrm{pH}$ meter from Hanna (USA) were used. UV lamp short wavelength $254 \mathrm{~nm}$ (Vilber Lournate $220 \mathrm{~V} 50 \mathrm{~Hz}$, Marne-la-Vallee Cedex, France) was used in the UV-degradation study.

\section{Materials and reagents}

All the chemicals used were of analytical reagent grade, and the solvents were of HPLC grade. Indacaterol maleate and glycopyrronium bromide reference substances were kindly provided by Novartis (Basel, Switzerland). Tenoxicam (TNX) as internal standard and maleic acid were obtained from Sigma Chemicals. Inhaler capsules containing $110 \mu \mathrm{g}$ of IND and $50 \mu \mathrm{g}$ of GLY/capsule (Ultibro ${ }^{\circledR}$ Breezhaler $^{\circledR}$ ), $150 \mu \mathrm{g}$ of IND/capsule (Onbrez Breezhaler ${ }^{\circledR}$ ) and $50 \mu \mathrm{g}$ of GLY/capsule (Seebri ${ }^{\circledR}$ Breezhaler ${ }^{\circledR}$ ) were obtained from commercial sources. Acetonitrile and methanol were purchased from SigmaAldrich (Germany). Orthophosphoric acid (85\% w/v) was obtained from Riedel-deHaën (Sleeze, Germany). Hydrochloric acid $(32 \% \mathrm{w} / \mathrm{v})$, hydrogen peroxide $(10 \% \mathrm{w} / \mathrm{v})$, sodium hydroxide and sodium dihydrogen phosphate were obtained from Adwic Co. (Cairo, Egypt). High purity distilled water was used in the study.

\section{Chromatographic conditions}

An Onyx Monolithic C18, $100 \times 4.6 \mathrm{~mm}$ (Phenomenex, Torrance, California, USA) thermostatted at $35{ }^{\circ} \mathrm{C}$ was used in this study. The mobile phase consisting of acetonitrile- $30 \mathrm{mM}$ phosphate buffer adjusted to $\mathrm{pH} 3.5$ with 
orthophosphoric acid (30:70, v/v) was filtered through a $0.45 \mu \mathrm{m}$ Millipore membrane filter under vacuum. The flow rate was $2.0 \mathrm{~mL} / \mathrm{min}$ and $\mathrm{UV}$ detection was set at $210 \mathrm{~nm}$.

\section{Standard solutions}

Stock solutions of $200 \mu \mathrm{g} / \mathrm{mL}$ of IND, GLY, and $500 \mu \mathrm{g} /$ mL TNX (IS) were individually prepared in methanol. These stock solutions were further diluted with the same solvent and then with the mobile phase as appropriate to obtain the working standard solutions. The stock solutions were stored at $4{ }^{\circ} \mathrm{C}$, protected from light.

\section{Construction of calibration graphs}

Aliquots of the suitable drug stock or working standard solutions were transferred into a series of $10-\mathrm{mL}$ volumetric flasks so that the final concentrations were in the range of $1-44 \mu \mathrm{g} / \mathrm{mL}$ for IND and $0.5-20 \mu \mathrm{g} / \mathrm{mL}$ for GLY. A constant $300 \mu \mathrm{L}$ TNX stock solution was added (final concentration of $15 \mu \mathrm{g} / \mathrm{mL}$ ) and the volumes were diluted to $10 \mathrm{~mL}$ with the mobile phase. The peak area ratio (peak area of the studied drug/peak area of TNX) was plotted versus the final concentration of each drug in $\mu \mathrm{g} / \mathrm{mL}$ to get the calibration graph. Alternatively, the corresponding regression equations were derived.

\section{Preparation of sample solutions}

Ten capsules from each formulation were emptied and the contents were weighted. A quantity of the powder equivalent to $440 \mu \mathrm{g}$ of IND and $200 \mu \mathrm{g}$ of GLY (Ultibro ${ }^{\circledR}$ Breezhaler $^{\circledR}$ ), $450 \mu \mathrm{g}$ of IND (Onbrez Breezhaler $^{\circledR}$ ) and $200 \mu \mathrm{g}$ of GLY (Seebri ${ }^{\circledR}$ Breezhaler $^{\circledR}$ ) was transferred into individual $10.0 \mathrm{~mL}$ volumetric flasks, sonicated with the mobile phase for $10 \mathrm{~min}$ and then the solution was completed to volume with the mobile phase. For analysis, an appropriate aliquot from the prepared sample solutions, spiked with $300 \mu \mathrm{L}$ TNX stock solution, was diluted to $10 \mathrm{~mL}$ using the same solvent. All solutions were filtered through a $0.45 \mu \mathrm{m}$ membrane filter before injection to the HPLC system. The nominal contents of the capsules were calculated using either the calibration graphs or the corresponding regression equations.

\section{Preparation of the degradation products}

$1 \mathrm{~mL}$ aliquots of each of the stock solutions of IND and GLY were transferred into a series of screw capped glass vials followed by $2 \mathrm{~mL}$ of distilled water, $0.1 \mathrm{M} \mathrm{HCl}, 0.1 \mathrm{M}$ $\mathrm{NaOH}$ or $10 \%$ hydrogen peroxide $\left(\mathrm{H}_{2} \mathrm{O}_{2}\right)$. The solutions were heated in a thermostatically controlled water bath at $80^{\circ} \mathrm{C}$ for $1 \mathrm{~h}$. At the specified time, the contents of the vials were cooled, and solutions under acidic and alkaline treatment were neutralized with $\mathrm{NaOH}$ and $\mathrm{HCl}$ solutions, respectively. Photo degradation was induced by exposing the samples to near ultraviolet $(254 \mathrm{~nm})$ light for $8 \mathrm{~h}$. The solutions were transferred into a series of $10 \mathrm{~mL}$ volumetric flasks. Then, $300 \mu \mathrm{L}$ of the IS solution was added, and the volumes were completed with the mobile phase. Solutions were mixed well and triplicate $20 \mu \mathrm{L}$ injections were made for each sample. The samples were analyzed against a freshly prepared control standard solution.

\section{Results and discussion}

The simultaneous separation and quantification of IND and GLY within the minimum analysis time and the maximum resolution and efficiency is the main objective of this study. The polarity of GLY and IND differ greatly, as GLY is less lipophilic than IND and their $\log$ P were found -1.2 and 3.31, respectively. The large difference in lipophilicity between GLY and IND posed a challenge in the development of the separation. The monolithic column was selected which yielded the advantage to optimize the separation of such drugs by utilizing an isocratic run. During our preliminary experiments, we tried several combinations of the mobile phase composition and $\mathrm{pH}$ in order to obtain the optimum separation.

\section{Method development and optimization Choice of detection wavelength}

Proper choice of the detection wavelength is crucial for the sensitivity of the method. The detection of IND and GLY was attempted at different wavelengths including 210, 220, 230 and $254 \mathrm{~nm} ; 210 \mathrm{~nm}$ was selected as the optimum detection wavelength allowing the detection of the two drugs and their degradation products with high sensitivity.

\section{Effect of $\mathrm{pH}$ and ionic strength of the buffer}

The effect of changing the $\mathrm{pH}$ of phosphate buffer solution was tested from 3.0 to 7.0. The increase in the $\mathrm{pH}$ from 4.0 to 7.0, caused loss of the peak sharpness and peak symmetry with a slight increase in retention time of both drugs. The peak shapes for the two drugs were sufficiently symmetrical only for $\mathrm{pH}$ value below 4.0. Little change is observed between $\mathrm{pH} 3.0$ and 4.0. So, pH 3.5 was found to be optimal. Studying the ionic strength of phosphate buffer (10-50 mM) revealed no significant effect on the separation process or the retention time of the two drugs. Hence, $30 \mathrm{mM}$ phosphate buffer was used as the aqueous phase in this study.

Variation of type and concentration of the organic modifier Two different organic solvents, methanol and acetonitrile were used. It was found that acetonitrile resulted in better sensitivity, shorter analysis time, and improvement in the peak shape compared with methanol. The influence 
of the amount of acetonitrile in the mobile phase was examined from 20 to $40 \%$. When acetonitrile content was increased to $40 \%$, the retention time of the two drugs was decreased with overlapping of their peaks. Whereas the use of $20 \%$ acetonitrile caused a delay in the elution with a decrease in the number of theoretical plates. A concentration of $30 \%$ acetonitrile was found to be the best compromise between selectivity and analysis time.

\section{Effect of column temperature and flow rate}

The influence of column temperature was examined in the range from 25 to $45{ }^{\circ} \mathrm{C}$. As expected at higher temperature, the retention of IND and GLY decreased, but the resolution between them decreased simultaneously. A temperature of $35{ }^{\circ} \mathrm{C}$ was found to give the best compromise to improve the repeatability between runs and reduce the analysis time.

The effect of the flow rate on the separation of the two drugs was also investigated. Good separation of IND and GLY with good peaks' shape and minimum retention times $(<3 \mathrm{~min})$ was obtained at a flow rate $2.0 \mathrm{~mL} / \mathrm{min}$.

\section{Internal standard selection}

For choosing a suitable internal standard, several drugs were tested. Tenoxicam was chosen as the best IS, giving a symmetrical peak; well separated from the two drugs and all the degradation products.

Under the mentioned chromatographic conditions highly symmetrical and sharp peaks of GLY and IND were obtained at retention times of 1.47 and $2.18 \mathrm{~min}$, respectively. The method was able to separate IND from its acidic counter ion (maleate). The peak due to counter ion was confirmed by injecting maleic acid solution and also by spiking in the drug solution to prove the elution at $0.71 \mathrm{~min}$. A typical chromatogram of a commercial sample of IND and GLY capsule is shown in Fig. 2.

\section{Method validation}

The method was validated according to the International Conference on Harmonization (ICH) guidelines [20, 21]. Different validation characteristics were investigated as follows:

\section{Linearity}

A linear relationship was established by plotting the peak area ratio against the drug concentration. The concentration ranges were found to be linear in the range of 1-44 and $0.5-20 \mu \mathrm{g} / \mathrm{mL}$ of IND and GLY, respectively. The values of the determination coefficient $\left(R^{2}\right)$ calculated were $0.9999(\mathrm{y}=1.345 \mathrm{x}+0.061)$ for IND and 0.9998 $(y=0.183 x+0.059)$ for GLY, indicating the linearity of the analytical curves for the method, where $\mathrm{x}$ is concentration and $y$ is the peak area ratio.

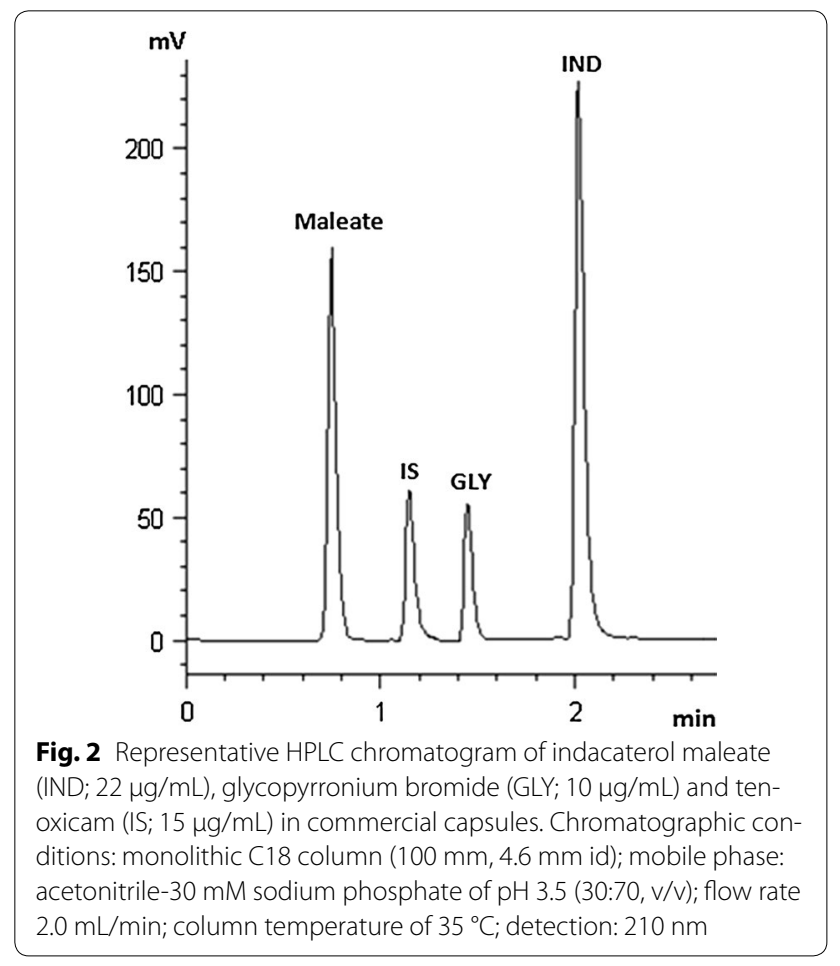

Limit of detection (LOD) and Limit of quantification (LOQ)

The LOD and LOQ for IND and GLY were determined based on signal-to-noise ratio of 3 and 10, respectively. The baseline noise was measured in a blank experiment in the region of retention time of IND and GLY using chromatographic software. It was found that for IND, the LOD and LOQ values were 0.06 and $0.16 \mu \mathrm{g} / \mathrm{mL}$ $(\mathrm{RSD}=0.82 \%)$, respectively and for GLY, the LOD and LOQ values were 0.12 and $0.34 \mu \mathrm{g} / \mathrm{mL}(\mathrm{RSD}=0.74 \%)$, respectively.

\section{Precision}

The precision of the method was evaluated as repeatability and intermediate precision. Repeatability was examined by threefold analyses of two preparations of $22 \mu \mathrm{g} /$ $\mathrm{mL}$ of IND and $10 \mu \mathrm{g} / \mathrm{mL}$ of GLY in 1 day. The RSD on the peak areas of these six determinations was not more than $0.46 \%$. Intermediate precision was also determined for three consecutive days. The RSD on the peak areas was not more than $1.13 \%$ suggesting that the proposed method is suitable for simultaneous analysis of IND and GLY in combined dosage forms.

\section{Accuracy}

Accuracy of the proposed method was determined by the standard addition method on the dosage form to which known amounts of IND and GLY standards have been added at different concentrations (IND: 5.5, 15, $22 \mu \mathrm{g} /$ 
mL; GLY: 2.5, 5, $10 \mu \mathrm{g} / \mathrm{mL}$ ). The determination was carried out using three replicates at each concentration level. The accuracy was determined as percent recovery of amount of analyte added to the sample. As shown in Table 1, the method was accurate within the desired range.

\section{Robustness}

The robustness of the developed method was investigated by evaluating the influence of small deliberate variations in experimental parameters like flow rate $( \pm 0.1 \mathrm{~mL} / \mathrm{min})$, detection wavelength $( \pm 2 \mathrm{~nm})$, buffer $\mathrm{pH}( \pm 0.2)$ and acetonitrile content $( \pm 2 \%)$. Resolution between GLY/ IND, theoretical plates and assay \% of the two drugs were determined for each modified condition. Table 2 shows the experiments performed for robustness evaluation. Therefore, it can be seen that these minor changes did not greatly affect the method performance.

\section{System suitability}

System suitability tests were performed to ensure that the HPLC system and the developed method are capable of providing quality data, based on USP 32 requirements [22]. The system suitability test carried out presented the following results: RSD values of 0.19 and $0.24 \%$ for the retention times, 0.78 and $1.12 \%$ for the peak areas, and 0.14 and $0.28 \%$ for the tailing factors, for GLY and IND, respectively. The number of theoretical plates was about 4725 and 4870 for GLY and IND,
Table 2 Robustness data for the proposed method

\begin{tabular}{|c|c|c|c|c|c|}
\hline \multirow[t]{2}{*}{ Variation } & \multirow[t]{2}{*}{ Resolution } & \multicolumn{2}{|c|}{$\begin{array}{l}\text { Theoretical } \\
\text { plates }\end{array}$} & \multicolumn{2}{|c|}{ Assay (\%) } \\
\hline & & IND & GLY & IND & GLY \\
\hline $28 \% \mathrm{ACN}$ & 4.81 & 4785 & 4658 & 99.86 & 100.23 \\
\hline $32 \% \mathrm{ACN}$ & 3.57 & 4924 & 4826 & 100.71 & 100.96 \\
\hline pH 3.3 & 4.13 & 4875 & 4732 & 100.49 & 100.91 \\
\hline $\mathrm{pH} 3.7$ & 4.32 & 4817 & 4715 & 100.37 & 100.35 \\
\hline Flow (1.9 mL) & 4.42 & 4858 & 4715 & 100.35 & 100.34 \\
\hline Flow (2.1 mL) & 3.91 & 4894 & 4737 & 100.52 & 100.87 \\
\hline Wavelength 208 (nm) & - & 4889 & 4734 & 100.73 & 101.14 \\
\hline Wavelength $212(\mathrm{~nm})$ & - & 4862 & 4719 & 100.29 & 100.12 \\
\hline Temperature $33^{\circ} \mathrm{C}$ & 4.33 & 4861 & 4712 & 100.3 & 100.24 \\
\hline Temperature $37^{\circ} \mathrm{C}$ & 4.14 & 4884 & 4741 & 100.61 & 100.81 \\
\hline Without variation & 4.25 & 4870 & 4725 & 100.43 & 100.62 \\
\hline
\end{tabular}

respectively. The experimental results showed that the parameters tested were within the acceptable range (RSD $<2.0 \%$ ), indicating that the method is suitable for the analysis intended.

\section{Stability of solutions}

The stability of standard working solutions as well as sample solutions in the diluting solvent (mobile phase) was examined and no chromatographic changes were observed within $8 \mathrm{~h}$ at room temperature and $48 \mathrm{~h}$ at $4{ }^{\circ} \mathrm{C}$. Also, the stock solutions prepared in HPLC-grade

Table 1 Accuracy of the proposed HPLC method

\begin{tabular}{|c|c|c|c|c|c|}
\hline \multirow{2}{*}{$\begin{array}{l}\text { Formulation } \\
\text { Ultibro }^{\circledR} \text { Breezhaler }^{\circledR}\end{array}$} & \multirow{2}{*}{$\begin{array}{l}\text { Concentration taken } \\
11,5 \mu \mathrm{g} / \mathrm{mL}\end{array}$} & \multicolumn{2}{|c|}{ Concentration added $(\mu \mathrm{g} / \mathrm{mL})$} & \multicolumn{2}{|l|}{ Accuracy $\%^{a}$} \\
\hline & & IND & GLY & IND & GLY \\
\hline & & 5.5 & 2.5 & 99.81 & 100.19 \\
\hline & & 15 & 5 & 100.34 & 101.02 \\
\hline & & 22 & 10 & 100.72 & 100.35 \\
\hline Mean $\% \pm S D$ & & & & $100.29 \pm 0.46$ & $100.52 \pm 0.44$ \\
\hline$\%$ RSD & & & & 0.46 & 0.44 \\
\hline \multirow[t]{4}{*}{ Onbrez Breezhaler ${ }^{\circledR}$} & $15 \mu \mathrm{g} / \mathrm{mL}$ & IND & & IND & \\
\hline & & 5.5 & & 101.09 & \\
\hline & & 15 & & 100.21 & \\
\hline & & 22 & & 99.78 & \\
\hline Mean $\% \pm S D$ & & & & $100.36 \pm 0.67$ & \\
\hline$\%$ RSD & & & & 0.67 & \\
\hline \multirow[t]{4}{*}{ Seebri ${ }^{\circledR}$ Breezhaler $^{\circledR}$} & $5 \mu \mathrm{g} / \mathrm{mL}$ & & GLY & & GLY \\
\hline & & & 2.5 & & 99.42 \\
\hline & & & 5 & & 100.37 \\
\hline & & & 10 & & 100.14 \\
\hline Mean $\% \pm S D$ & & & & & $99.98 \pm 0.49$ \\
\hline$\%$ RSD & & & & & 0.49 \\
\hline
\end{tabular}

${ }^{a}$ Each result is the average of three separate determinations 
methanol were stable for at least 2 weeks when stored refrigerated at $4{ }^{\circ} \mathrm{C}$. Retention times and peak areas of the drugs remained unchanged and no significant degradation was observed during these periods.

\section{Forced-degradation and stability-indicating aspects}

The presence of degradants and impurities in pharmaceutical formulations can result in changes in their chemical, pharmacological, and toxicological properties affecting their efficacy and safety of the drugs [23]. Therefore, the adoption of stability-indicating methods is always required to control the quality of pharmaceuticals during and after the production. This greatly contributes to the possibility of improving drug safety [24]. After acid, alkaline, and neutral hydrolysis of IND, the content of the drug decreased (31.1, 33.5, and 3.8\%, respectively). An additional peak was also observed in alkaline and acidic conditions. Under oxidative conditions, IND remained $61.4 \%$ intact without any additional peak. Under the photolytic conditions, IND content exhibited a $48.7 \%$ decrease of the area after $8 \mathrm{~h}$, and one degradation product was detected. Figure 3A shows the chromatograms of the IND forced degradation studies. Under the acidic hydrolysis, GLY content exhibited a decrease of its area (17.6\%) after $1 \mathrm{~h}$ in $0.1 \mathrm{M} \mathrm{HCl}$ solution, and three additional peaks were detected. Under the basic hydrolysis, nearly $95.8 \%$ of the GLY was degraded after $1 \mathrm{~h}$ in $0.1 \mathrm{M} \mathrm{NaOH}$ solution, and three additional peaks were detected. GLY was stable under neutral hydrolysis for $1 \mathrm{~h}$. Just one additional peak was also detected in the oxidative condition with a $49.5 \%$ decrease of the GLY peak. For the photolytic condition, $21.7 \%$ of the GLY was degraded after $8 \mathrm{~h}$ and one degradation product was detected. The chromatograms of the forced degradation studies of GLY are represented in Fig. 3B.

\section{Application of the proposed method to pharmaceutical analysis}

The proposed method was successfully applied for the determination of IND and GLY both individually and in combined dosage capsules formulations. No interfering peaks were observed in the recorded chromatograms indicating that there is no interference effect resulting from excipients used in the production of capsules. The results obtained are accurate and precise as indicated by

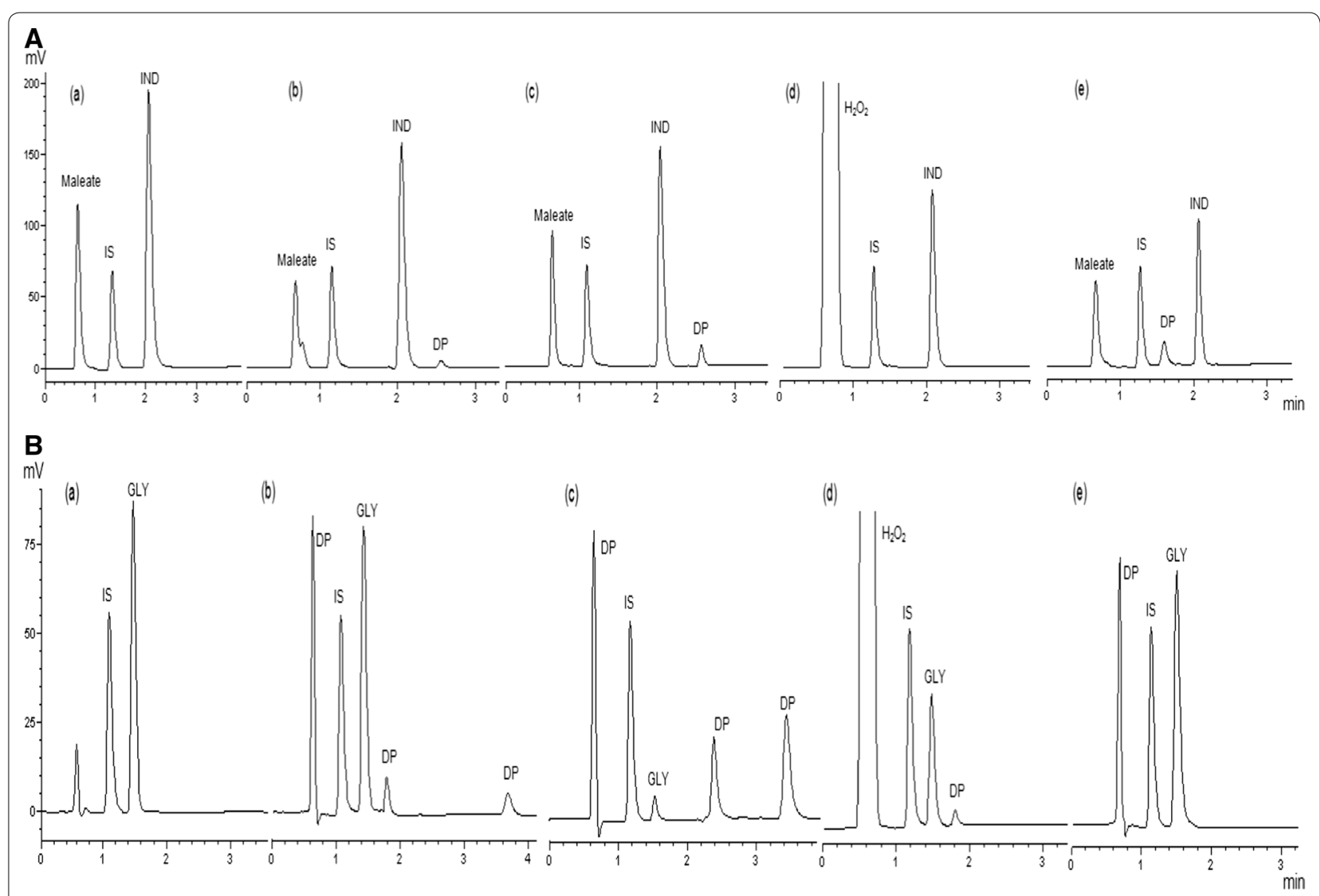

Fig. $3 \mathrm{HPLC}$ chromatograms of $\mathbf{A}$ indacaterol maleate (IND; $20 \mu \mathrm{g} / \mathrm{mL}$ ) and $\mathbf{B}$ glycopyrronium bromide (GLY; $20 \mu \mathrm{g} / \mathrm{mL}$ ) after (a) neutral hydrolysis (b) acidic hydrolysis; (c) alkaline hydrolysis; (d) oxidation and (e) exposition to UV light. IS internal standard (15 $\mu \mathrm{g} / \mathrm{mL}), D P$ degraded products 
Table 3 Determination of IND and GLY in commercial inhaler capsules

\begin{tabular}{|c|c|c|c|c|c|c|}
\hline \multirow[t]{2}{*}{ Formulation } & \multicolumn{2}{|c|}{ Labelled amount } & \multicolumn{2}{|c|}{ Mean found } & \multicolumn{2}{|l|}{ Recovery $^{\mathrm{a}}(\%)$} \\
\hline & IND & GLY & IND & GLY & IND & GLY \\
\hline Ultibro ${ }^{\circledR}$ Breezhaler $^{\circledR}$ & 110 & 50 & 110.73 & 50.58 & $100.67 \pm 0.35$ & $101.16 \pm 0.47$ \\
\hline Onbrez Breezhaler ${ }^{\circledR}$ & 150 & - & 150.54 & - & $100.36 \pm 0.26$ & - \\
\hline Seebri ${ }^{\circledR}$ Breezhaler $^{\circledR}$ & - & 50 & - & 50.25 & - & $100.49 \pm 0.56$ \\
\hline
\end{tabular}

${ }^{a}$ Each result is the average of three separate determinations

the excellent percentage recovery (Table 3 ). The assay results obtained has shown that the method is suitable for the quality control analysis of IND and GLY.

\section{Conclusion}

A simple, rapid, and accurate LC method was developed for the simultaneous determination of IND and GLY in pharmaceutical inhaler capsules using monolithic column. The LC method was validated and demonstrated good linearity, precision, accuracy and specificity without any interference from the excipients and degradation products. The proposed method could be adopted in quality control laboratories for the analysis of these two drugs individually or in combination.

\begin{abstract}
Abbreviations
IND: indacaterol maleate; GLY: glycopyrronium bromide; COPD: chronic obstructive pulmonary disease; HPLC: high performace liquid chromatography; ICH: International Conference on Harmonization; LOQ: Iimit of quantification; LOD: limit of detection.
\end{abstract}

\section{Authors' contributions}

SZ proposed the subject, participated in the study design, the assay design, literature review, conducted the validation of the assay, analysis of the samples, and the preparation and writing of the manuscript. FB designed the study, participated in the results discussion and revised the manuscript. Both authors read and approved the final manuscript.

\section{Author details}

${ }^{1}$ Unit of Drug Analysis, Faculty of Pharmacy, University of Mansoura, Mansoura 35516, Egypt. ${ }^{2}$ Pharmaceutical Analytical Chemistry Department, Faculty of Pharmacy, University of Mansoura, Mansoura 35516, Egypt.

\section{Competing interests}

The authors declare that they have no competing interests.

\section{Publisher's Note}

Springer Nature remains neutral with regard to jurisdictional claims in published maps and institutional affiliations.

Received: 19 December 2016 Accepted: 27 April 2017

Published online: 04 May 2017

\section{References}

1. Gershon AS, Warner L, Cascagnette P, Charles Victor J (2011) Lifetime risk of developing chronic obstructive pulmonary disease: a longitudinal population study. Lancet 378:991-996
2. Ray SM, McMillen JC, Treadway SA, Helmer RS, Franks AS (2012) Indacaterol: a novel long-acting $\beta$ (2)-agonist. Pharmacotherapy 32:456-474

3. Ulrik CS (2012) Once-daily glycopyrronium bromide, a long-acting muscarinic antagonist, for chronic obstructive pulmonary disease: a systematic review of clinical benefit. Int J COPD 7:673-678

4. Vincken W, Aumann J, Chen H, Henley M, McBryan D, Goyal P (2014) Efficacy and safety of coadministration of once-daily indacaterol and glycopyrronium versus indacaterol alone in COPD patients: the GLOW6 study. Int J Chronic Obstr Pulm Dis 9:215-228

5. El-Ashry SM, El-Wasseef DR, El-Sherbiny DT, Salem YA (2015) Spectrophotometric and spectrofluorimetric determination of indacaterol maleate in pure form and pharmaceutical preparations: application to content uniformity. Luminescence 30:891-897

6. Abdel Ghany MF, Hussein LA, Magdy N, Yamani HZ (2016) Simultaneous spectrophotometric determination of indacaterol and glycopyrronium in a newly approved pharmaceutical formulation using different signal processing techniques of ratio spectra. Spectrochim Acta A Mol Biomol Spectrosc 157:251-257

7. Nebiu D, Walter M, Lachmann B, Kopelent H, Noe CR (2007) Determination of $(R, R)$-glycopyrronium bromide and its related impurities by ionpair HPLC. Pharmazie 62:406-410

8. Murray GR, Calvey TN, Williams NE, Chan K (1984) Quantitative capillary column gas chromatographic method for the determination of glycopyrronium in human plasma. J Chromatogr B 308:143-151

9. Emotte C, Heudi O, Deglave F, Bonvie A, Masson L, Picard F, Chaturvedi A, Majumdar T, Agarwal A, Woessner R, Kretz O (2012) Validation of an on-line solid-phase extraction method coupled to liquid chromatography-tandem mass spectrometry detection for the determination of indacaterol in human serum. J Chromatogr B 895-896:1-9

10. Ammari WG, Al-Qadhi Z, Khalil M, Tayyem RQ, Oriquat G, Basheti IA, Chrystyn $\mathrm{H}$ (2014) Indacaterol determination in human urine: validation of a Liquid-Liquid extraction and liquid chromatography-tandem mass spectrometry analytical method. J Aerosol Med Pulm Drug Deliv 28:202-210

11. Ammari WG, Al-Qadhi Z, Khalil M, Tayyem RQ, Oriquat G, Basheti IA, Chrystyn H (2015) Validated liquid chromatography-tandem mass spectrometry coupled with liquid-liquid extraction for indacaterol quantitation in human plasma. Adv Pharmacol Pharm 3:43-51

12. Matassa LC, Woodard D, Leavitt RK, Firby P, Beaumier P (1992) Solid-phase extraction techniques for the determination of glycopyrrolate from equine urine by liquid chromatography-tandem mass spectrometry and gas chromatography-mass spectrometry. J Chromatogr 573:43-48

13. Storme ML, Kindt RS, Goeteyn W, Reyntjens K, Van Bocxlaer JF (2008) Quantitative determination of glycopyrrolate in human plasma by liquid chromatography-electrospray ionization mass spectrometry: the use of a volatile ion-pairing agent during both liquid-liquid extraction and liquid chromatography. J Chromatogr B 876:24-30

14. Rumpler MJ, Sams RA, Colahan P (2011) Validation of a liquid chromatography-tandem mass spectrometry method for quantification of glycopyrrolate in horse plasma. J Anal Toxicol 35:656-664

15. Gorog S (2007) The changing face of pharmaceutical analysis. Trends Anal Chem 26:12-17

16. Guillarme D, Nguyen DT, Rudaz S, Veuthey JL (2007) Recent developments in liquid chromatography_impact on qualitative and quantitative performance. J Chromatogr A 1149(1):20-25 
17. Miyabe K, Guiochon G (2004) Characterization of monolithic columns for HPLC. J Sep Sci 27:853-873

18. Watanabe F, KuboT Kaya K, Hosoya K (2009) Novel separation medium spongy monolith for high throughput analyses. J Chromatogr A 1216:7402-7408

19. Columns Chromolith (2012) Application note. Merck, Germany

20. International Conference on Harmonization (ICH) (2003). Technical requirements for the registration of pharmaceutical for human use, stability testing of new drugs substance and products Q1A (R2). 1

21. International Conference on Harmonization (ICH) (2005). Technical requirements for the registration of pharmaceutical for human use, validation of analytical procedures: text and methodology Q2(R1). 1
22. The United States Pharmacopeia (2009) USP 32. United States Pharmacopeial Convention, Rockville

23. Alsante KM, Ando A, Brown R, Ensing J, Hatajik TD, Kong W, Tsuda Y (2007) The role of degradant profiling in active pharmaceutical ingredients and drug products. Adv Drug Deliv Rev 59:29-37

24. Go"ro"g S (2008) Drug Safety, Drug Quality, Drug Analysis. J Pharm Biomed Anal 48:247-253

\section{Submit your manuscript to a SpringerOpen ${ }^{\circ}$ journal and benefit from:}

- Convenient online submission

\section{- Rigorous peer review}

- Immediate publication on acceptance

- Open access: articles freely available online

- High visibility within the field

- Retaining the copyright to your article 